OPEN ACCESS

Edited by:

Robert W. Maitta,

Case Western Reserve University,

United States

Reviewed by:

Sezaneh Haghpanah,

Shiraz University of Medical

Sciences, Iran

Mohsen Saleh Elalfy,

Ain Sham University, Egypt

*Correspondence:

Argiris Symeonidis

argiris.symeonidis@yahoo.gr orcid.org/0000-0002-3685-3473

Specialty section:

This article was submitted to Hematology,

a section of the journal

Frontiers in Medicine

Received: 29 December 2021

Accepted: 10 January 2022

Published: 16 February 2022

Citation:

Matsagos S, Verigou E, Kourakli A, Alexis S, Vrakas S, Argyropoulou C,

Lazaris V, Spyropoulou P,

Labropoulou V, Georgara N,

Lykouresi M, Karakantza M, Alepi C and Symeonidis A (2022) High Frequency of Post-Transfusion

Microchimerism Among

Multi-Transfused Beta-Thalassemic

Patients. Front. Med. 9:845490.

doi: 10.3389/fmed.2022.845490

\section{High Frequency of Post-Transfusion Microchimerism Among Multi-Transfused Beta-Thalassemic Patients}

\author{
Spyridon Matsagos 1,2 , Evgenia Verigou ${ }^{2}$, Alexandra Kourakli ${ }^{2}$, Spyridon Alexis ${ }^{2}$, \\ Spyridon Vrakas ${ }^{3}$, Constantina Argyropoulou ${ }^{2}$, Vasileios Lazaris ${ }^{2}$, \\ Panagiota Spyropoulou ${ }^{1}$, Vasiliki Labropoulou ${ }^{2}$, Nicoletta Georgara ${ }^{4}$, Maria Lykouresi ${ }^{1}$, \\ Marina Karakantza ${ }^{5}$, Chrysoula Alepi ${ }^{1}$ and Argiris Symeonidis ${ }^{2 *}$ \\ 'Department of Transfusion Medicine and Blood Bank, "Tzaneion" General Hospital, Piraeus, Greece, ${ }^{2}$ Hematology Division, \\ Department of Internal Medicine, University of Patras Medical School, Patras, Greece, ${ }^{3}$ Gastroenterology Department, \\ "Tzaneion" General Hospital, Piraeus, Greece, ${ }^{4}$ Department of Transfusion Medicine and Blood Bank, University Regional \\ General Hospital of Patras, Patras, Greece, ${ }^{5}$ Haematology and Transfusion Department, National Health Service Blood and \\ Transplant, Leeds Teaching, Hospital Trust, Leeds, United Kingdom
}

Background: Transfusion-associated microchimerism implies the presence of allogeneic hematopoietic cells in an individual, following the transfusion of a blood product. It is a transfusion-related adverse effect/long-term consequence, which has not been well-investigated among regularly transfused patients with thalassemia.

Patients and Methods: We investigated 64 regularly transfused, homozygous $\beta$-thalassemic patients and 21 never-transfused healthy volunteer blood donors (controls) for the presence of microchimerism in their sera, using real-time PCR targeting circulating allogeneic, both, Human Leukocyte Antigen-DR isotype (HLA-DR) and non-HLA alleles. The investigation was longitudinally repeated in patient subsets for more than 2 years. Results were correlated with clinical and laboratory parameters, peripheral blood lymphocyte immunophenotype, blood storage time, and donor's gender to identify potential contributing factors for microchimerism generation.

Results: Overall, microchimerism was detected in 52 of the 64 patients (81.2\%) and in 6 of the 21 controls (28.5\%, $p=0.0001)$. Forty-four patients (68.7\%) exhibited long-term microchimerism (persisted for more than 6 months), confirmed at all time-points investigated. Microchimerism was more frequent among elderly, women, splenectomized and more heavily transfused patients, and among those who exhibit higher serum ferritin levels. In these patients, a distinct descending pattern of CD16 ${ }^{\mathrm{dim}}+\mathrm{CD}^{\mathrm{dim}}+$ natural killer (NK)-cells $(p<0.001)$ and an ascending pattern of CD4+CD25 bright CD127regulatory T-cells $(p=0.022)$ for increasing allelic burden were noticed, suggesting the establishment of recipient immune tolerance against the donor-derived chimeric alleles. Both splenectomized and non-splenectomized thalassemic patients exhibited the same trend. The storage time of transfused blood products and donor/gender mismatch had no impact on the development of microchimerism. 
Discussion-Conclusive Remarks: Transfusion-associated microchimerism appears to be a very common complication among multi-transfused thalassemic patients. The potential clinical consequences of this phenomenon remain as yet unclear. Immune tolerance attributed to disease itself and to repeated transfusions might at least in part explain its appearance.

Keywords: thalassemia, transfusion, adverse effects, microchimerism, immunomodulation

\section{INTRODUCTION}

Beta ( $\beta$ )-thalassemias represent a group of hereditary disorders of hemoglobin synthesis, characterized by $\beta$-globin chain deficiency, either due to gene hypo-transcription, resulting from mutations of the promoter area, or from the production of a dysfunctional $\beta$-globin chain, leading to the formation of an unstable tetramer (1). The prevalence of $\beta$-thalassemia is higher across the Mediterranean countries, namely, Greece (2), where the frequency of $\beta$-thalassemia heterozygotes is estimated to be $6-8 \%$, but in certain endemic areas may reach $15-20 \%$ (3). Patients with transfusion-dependent $\beta$-thalassemia (TDT) do not use their own erythropoiesis at all, have usually received their first transfusion course before the completion of their second year of life and require a lifelong regular red blood cell (RBC) transfusion program consisted of at least one transfusion course per month, to maintain adequate hemoglobin levels, adapted to the degree of their impaired erythropoiesis. Adequacy of RBC transfusions, coupled with an effective iron chelation regimen, represents the main therapeutic interventions for these patients, to secure normal growth and prevent end-organ complications. Moreover, many patients with non-transfusiondependent thalassemia (NTDT) defined as those, who do not require a regular transfusion program, rely to a variable degree on their own erythropoiesis and they usually receive less than 6 transfusion courses per year, as well as those with sicklecell $/ \beta$-Thalassemia may transiently or permanently become transfusion-dependent at an unpredicted time point in their life $(4,5)$.

Although RBC transfusion is a routine clinical procedure for several decades, with low frequency of adverse effects, disguise some obscure and unpredicted long-term complications. Transfusion-associated complications have been well-recognized and characterized and are classified in two main categories: acuteoccurring or delayed reactions and long-term consequences, such as alloimmunization, iron overload, graft vs. host disease, and microchimerism. For highly transfused patients with TDT, the risk of such complications is anticipated to be higher. The lastly mentioned long-term consequence, namely, transfusionassociated microchimerism (TA-MC) is not easily documented in routine clinical practice and has not yet been very wellcharacterized, particularly, in this patient population (6).

Transfusion of any blood product has been associated with the risk of long-term engraftment of donor-derived genetic material in the recipient, but the potential implications of this finding have not been studied sufficiently. Microchimerism in general is defined as the presence of a small percentage (3$5 \%$ ) of allogeneic hemato/lymphopoietic cells in an individual, following the transfusion of a blood product, transplantation, or pregnancy (7-11). TA-MC was initially described in 1977, as the cytogenetic evidence of donor-derived leucocyte proliferation within 7 days following RBC transfusions (12). It has mainly been studied among trauma patients, its real frequency is unknown, but surprisingly, there is a paucity of data for multitransfused patients with congenital or acquired blood disorders, requiring regular RBC transfusions. For trauma patients, who are transfused for a short period of time, it is also unknown why they develop, not only short-term (the existence of chimeric cells $\leq 6$ months) but even long-term (the existence of chimeric cells $>6$ months) TA-MC (13-16) and which factors favor this complication (17).

This study aimed to investigate the frequency of TA-MC of all types (either short- or long-term) in a representative group of patients with thalassemic in Greece to detect and quantify microchimerism, assess its clinical significance and its consequences, and identify potentially existing predisposing factors for its appearance.

\section{PATIENTS AND METHODS}

\section{Study Population}

Overall, 205 samples from 85 individuals were examined between March 2013 and May 2016. Sixty-four were thalassemic patients (target group, women $N=32$, men $N=32$, median age 42 years, range $22-60$ years) and 21 were never-transfused male volunteer blood donors randomly selected during the study period (control group, median age 41 years, range $24-53$ years, p:n.s.). Patients were tested 14-16 days following their previous RBC transfusion, whereas for controls, an extra ethylenediaminetetraacetic acid (EDTA) tube was collected, during the blood donation course. All patients with TDT received concentrated and leucocyte-depleted RBC (18), and all participated subjects were thoroughly informed about the study and signed informed consent. The study was approved by the Ethical and Scientific Committee of the Tzaneion Hospital (5th issue of the 17th Meeting of the Committee in June 13, 2012).

To investigate the duration of TA-MC existence, 57 of the 64 patients (89\%) were re-tested after a median of 9.5 months, and among them, 21 non-completely transfusion-dependent (NTDT patients) were examined for a third time, following a median of 17.6 months from the second test and 26.4 months from the baseline one.

\section{Sample Processing}

Peripheral blood samples were collected upon arrival to the Hospital, before the scheduled transfusion course, so that the 


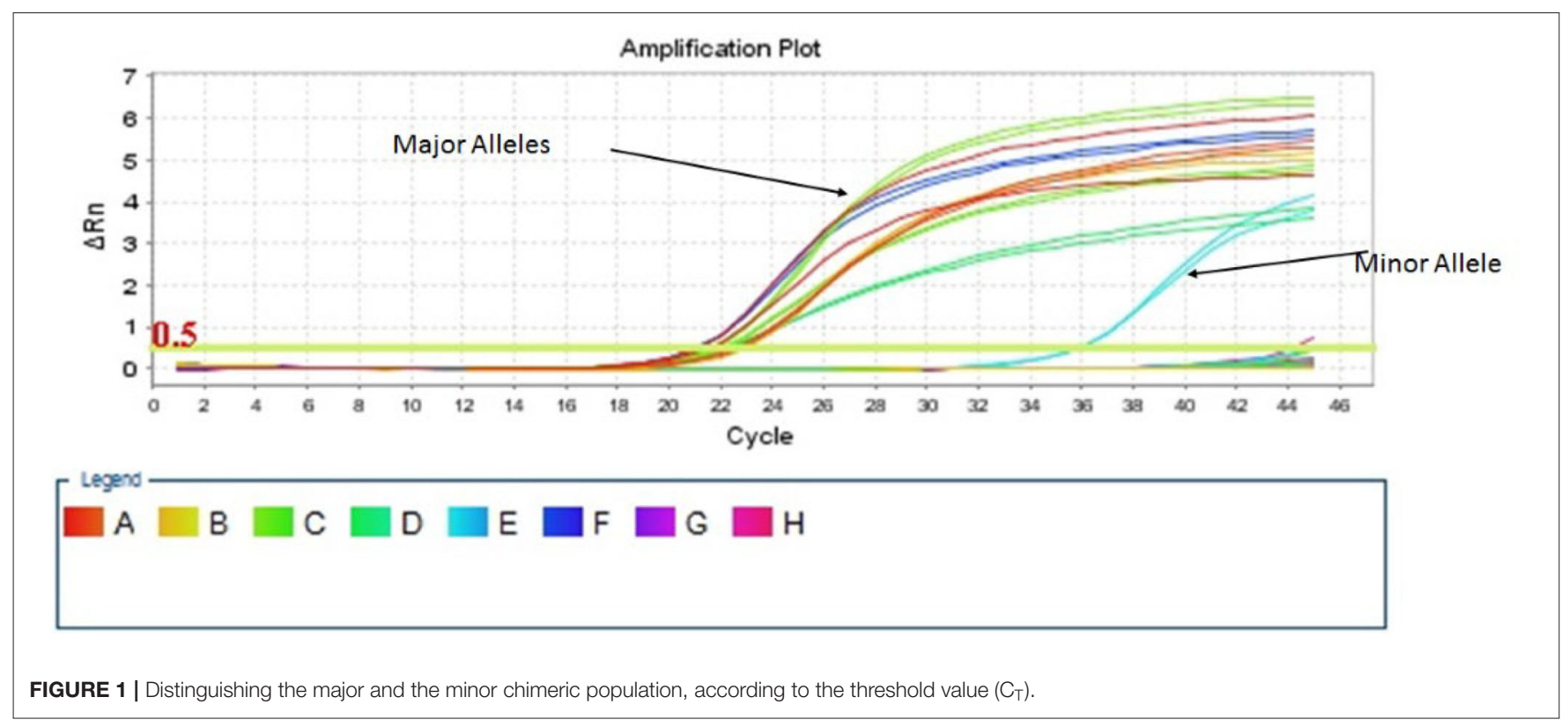

TABLE 1 | Sequences of primers for the HLA-DR panel.

\begin{tabular}{|c|c|c|}
\hline Primer name & Forward & Reverse \\
\hline DR1 & CTTGTGGCAGCTTAAGTTGAATG & GGACTCCTCTTGGTTATAGATGCA \\
\hline DR3 & TACTTCCATAACCAGGAGGAGA & TGCAGTAGTTGTCCACCCG \\
\hline DR7 & CCTGTGGCAGGGTAAGTATA & CCCGTAGTTGTGTCTGCACAC \\
\hline DR8 & AGTACTCTACGGGTGAGTGTT & CTGCAGTAGGTGTCCACCAG \\
\hline DR11 & GTTCTTGGAGTACTCTACGTC & CTGGCTGTTCCAGTACTCCT \\
\hline DR12 & AGTACTCTACGGGTGAGTGTT & САCTGTGAAGCTCTCTCCACAG \\
\hline DR13 & TACTTCCATAACCAGGAGGAGA & CCCGCTCGTCTTCCAGGAT \\
\hline DR15 & CTGTGGCAGCCTAAGAGGGAGT & CCGCGCCTGCTCCAGGAT \\
\hline DR16 & CTGTGGCAGCCTAAGAGGGAGT & AGGTGTCCACCGCGGCG \\
\hline
\end{tabular}

last transfusion had been administered at least 14 days before sampling. Specimens were drawn in $5 \mathrm{ml}$ EDTA tubes and were frozen immediately at $-80^{\circ} \mathrm{C}$. Samples were thawed for analysis at room temperature and blood lysates were prepared, using the PureLink Genomic DNA Mini Kit (Invitrogen, Thermo Fisher Scientific, USA). Lysates proceeded to DNA isolation and purification, using a spin column-based centrifugation. DNA was washed and eluted with $100 \mu \mathrm{l}$ of Elution Buffer. DNA concentration was quantified by an ND-2000 spectrophotometer (NanoDrop, Thermo Scientific, USA).

\section{Microchimerism Assessment}

For TA-MC detection, two quantitative, allele-specific realtime PCR (QAS-PCR) assays were used, based in the work of Alizadeh et al. (19) and the adoption and optimization for Microchimerism detection from Lee et al. (20) They first detect minor leucocyte subpopulations, targeting allogeneic HLA-DR alleles, whereas the second works complementarily, detecting non-HLA loci on nine chromosomes, for naturally occurring insertion-deletion polymorphisms (S01-S011) $(19,20)$. Negative and positive controls for both panels were run in parallel with patients' samples. A mixture of $10 \mu \mathrm{l}$ total PCR volume per well was needed, consisting of $5 \mu \mathrm{l}$ PowerUp SYBR Green Master Mix (Applied Biosystems, Life Technologies, USA), 2 $\mu \mathrm{l}$ of Forward and Reverse primers and variable volumes of cDNA template and RNase-free water, depending on the DNA concentration of each sample, considering $100 \mathrm{ng} / \mu \mathrm{l}$ as the desirable DNA concentration. Pre-amplification procedures were carried out in a separate room from the amplification one, to avoid contamination. Real-time PCR was performed with the StepOnePlus System (Applied Biosystems, USA), using the following cycle conditions: $10 \mathrm{~min}$ at $95^{\circ} \mathrm{C}$, followed by 45 cycles of $30 \mathrm{~s}$ at $95^{\circ} \mathrm{C}, 30 \mathrm{~s}$ at $64^{\circ} \mathrm{C}$, and $45 \mathrm{~s}$ at $72^{\circ} \mathrm{C}$. A Melt Curve Cycling stage was performed with $15 \mathrm{~s}$ at $95^{\circ} \mathrm{C}$, 
TABLE 2 | Sequences of primers for the insertion-deletion polymorphisms panel.

\begin{tabular}{|c|c|c|}
\hline Primer name & Forward & Reverse \\
\hline S 01 & GGTACCGGGTCTCCACATGA & GGGAAAGTCACTCACCCAAGG \\
\hline S 02 & GCTTCTCTGGTTGGAGTCACG & GCTTGCTGGCGGACCCT \\
\hline so-3 & CTITGCTाCTGTTCTTAAGGGC & TCAATCTITGGGCAGGTTGAA \\
\hline SO-4 & CTGGTGCCCACAGTTACGCT & AAGGATGCGTGACTGCTATGG \\
\hline SO-4B & CAGTCACCCCGTGAAGTCCT & AGGATGCGTGACTGCTCCTC \\
\hline SO-7B & CTGGATGCCTCACTGATCCA & CAGCTGCAACAGTTATCAACGTT \\
\hline SO-8 & GCTGGATGCCTCACTGATGTT & TGGGAAGGATGCATATGATCTG \\
\hline SO-8B & GGGCACCCGTGTGAGTIT & TCAGCTTGTCTGCTITCTGGAA \\
\hline SO-9 & TAGGATTCAACCCTGGAAGC & CCAGCATGCACCTGACTAACA \\
\hline SO-11 & GGACTGAGGCTCCCACCTIT & GCATGGACTGTGGTCTGCAA \\
\hline
\end{tabular}

$1 \mathrm{~min}$ at $60^{\circ} \mathrm{C}$, and $15 \mathrm{~s}$ at $95^{\circ} \mathrm{C}$, to assess the specificity of amplified products. Results were analyzed, using the Relative Quantification Method $\left(\Delta \Delta \mathrm{C}_{\mathrm{T}}\right)$, with the StepOne Software v2.3 showing the ratio between the major and the minor populations (Life Technologies, USA). The patient's major TA-MC type was expected to exist in many DNA copies and cross the threshold value $\left(\mathrm{C}_{\mathrm{T}}\right)$ at a low cycle number. Conversely, the donor's minor type (microchimeric cells) was expected to have higher $\mathrm{C}_{\mathrm{T}}$, making the two populations distinguishable, since fewer DNA copies would exist, and more replication cycles would be necessary to make them detectable (Figure 1). All PCRs were performed in duplicate and most positive samples were re-tested to exclude false-positive results. Microchimerism was defined by the appearance of minor alleles with a cycle threshold 810 cycles later than the major sequence pattern for the InDel panel. The major allelic population amplifies between 19 and 24 cycles while the minor population amplifies between 27 and 34 cycles (18). Respectively, for the HLA panel, the major alleles amplified on an early cycle 19 up to 26 and minor between 27 and 36. However, as have been previously reported, the concentration of the minor alleles can be extremely low after the first exposure and this kind of alleles increased over years, until stabilization to a level as much as $4 \%$ of all circulating white blood cells (WBCs) (20) This is the reason that every PCR signal cannot be ignored or characterized as noise but have to be carefully checked and retested. Positivity beyond the above $\mathrm{C}_{\mathrm{T}}$, was characterized as low $\left(\mathrm{C}_{\mathrm{T}} \geq 33-36.9\right)$, very low $\left(\mathrm{C}_{\mathrm{T}} \geq 37\right.$ 40.9), and borderline $\left(C_{T} \geq 41-42.9\right)$, when these results were confirmed by a new confirmatory PCR. This positivity is most likely to be attributed to different microchimerism levels, but rarely due to contamination. Contamination issues have been avoided by checking the three duplicated negative controls that "ran" in every PCR plate. Reproducibility for patients' major alleles, for two up to three different time points (by testing different samples), was also a verification for our results.

The sequences of primers used for the detection of HLA-DR alleles and of Insertion-Deletion Polymorphisms are shown in Tables 1, 2, respectively.
TABLE 3 | Flow cytometry analysis panel used for the detection of various lymphocyte subpopulations.

\begin{tabular}{llll}
\hline Color & $\begin{array}{l}\text { Protocol } \\
\text { 1: NK, } \\
\text { NK-T, and } \\
\text { CD8 } \\
\text { cytotoxic }\end{array}$ & $\begin{array}{l}\text { Protocol } \\
\text { 2: T-cells, } \\
\text { T-reg, and } \\
\text { activation } \\
\text { status }\end{array}$ & $\begin{array}{l}\text { Protocol 3: } \\
\text { Memory, }\end{array}$ \\
& CD3 & $\begin{array}{l}\text { cells, and } \\
\text { monocytes }\end{array}$ \\
\hline FITC & CD16+CD56 & CD127 & CD45RO \\
PE & CD8 & CD25 & CD14 \\
ECD & CD4 & HLA DR & CD8 \\
PC5 & CD45 & CD4 & CD20 \\
PC7 & & CD3 & CD45
\end{tabular}

\section{Flow Cytometry Analysis}

Following an interim analysis of the obtained results from the first 18 patients, we decided to investigate the peripheral blood immunophenotype profile of our patients. Thus, a sub-cohort of 9 out of the 12 patients (75\%) who did not exhibit TA-MC, and 42 of the $52(81 \%)$, who exhibited TA-MC, were analyzed immunophenotypically at a median of 5.7 months (range 0-9 months) following the detection of TA-MC. In these 51 patients, there were 25 women and 26 men, and gender distribution was not significantly different between the two subgroups, according to the manifestation of TA-MC.

Peripheral blood lymphocyte subpopulations were estimated, using three 5-color protocols, formulated as shown in Table 3. The panel consisted of 12 monoclonal antibodies, targeting the basic T-helper (CD3+CD4+), cytotoxic $\left(\mathrm{CD} 3+\mathrm{CD} 8^{\mathrm{dim}}+\right.$ and $\left.\mathrm{CD} 3+\mathrm{CD} 8^{\text {bright }}\right)$, regulatory $\left(\mathrm{CD} 3+\mathrm{CD} 4+\mathrm{CD} 25^{\text {bright }}+\mathrm{CD} 127-\right), \mathrm{B}(\mathrm{CD} 20+)$, natural killer (NK; CD3-CD16 $6^{\text {bright }}+$ and/or $\mathrm{CD} 56^{\text {bright }}+\mathrm{CD} 8+/ \mathrm{CD} 3-$ CD56 $\left.{ }^{\mathrm{dim}} \mathrm{CD} 16^{\mathrm{dim}}\right), \mathrm{NK} / \mathrm{T}(\mathrm{CD} 3+\mathrm{CD} 16+\mathrm{CD} 56+)$, and the $\mathrm{NK} / \mathrm{T}$ subset $\mathrm{CD} 3^{\text {bright }} \mathrm{CD} 16+\mathrm{CD} 56+$ (most probably $\mathrm{T}_{\gamma \delta}$ ), memory cells (CD45RO+), and lymphocytic middle (CD25+) and late (HLA-DR+) activation status. All monoclonal antibodies were purchased from Beckman Coulter, USA. 


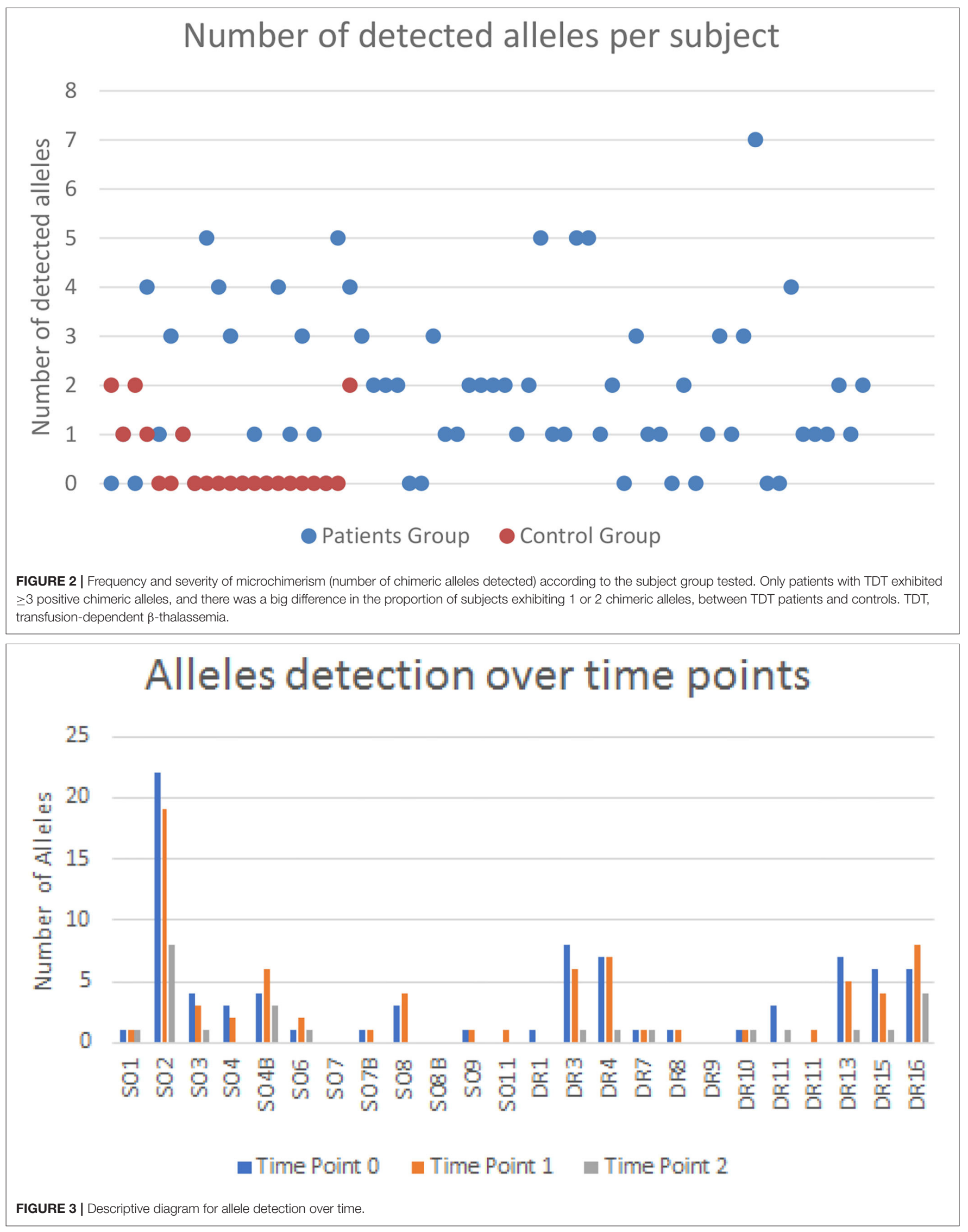




\section{Sample Preparation}

Sample preparation was conducted within $24 \mathrm{~h}$ of acquisition. A mixture of $75 \mu \mathrm{l}$ of whole peripheral blood with the monoclonal antibodies, at a volume of $13 \mu \mathrm{l}$ for fluorescein isothiocyanate (FITC) and phycoerythrin (PE) conjugates and $7 \mu \mathrm{l}$ for ECD, PC5, and PC7 conjugates, respectively, was prepared and incubated for $15 \mathrm{~min}$ at room temperature, protected from light. A $1.5 \mathrm{ml}$ of $\mathrm{BD}$ Pharm Lyse diluted to $1 \times$ concentration was used to lyse RBC, following antibody staining, at a final volume of $1.5 \mathrm{ml}$ for $15 \mathrm{~min}$. Flow cytometry sample acquisition was performed immediately after sample preparation, using an FC 500 Cytometer (Beckman Coulter, USA).

\section{Statistical Analysis}

Comparisons of parametric data were made using Student's $t$ test or one-way ANOVA for variables with normal distribution. For non-parametric data, the Mann-Whitney $U$-test was used to compare differences between two groups, and KruskalWallis and independent samples median tests for comparisons between more than two groups were used. A $p$ of $<0.05$ was considered statistically significant. Correlations between the number of chimeric alleles and percentages of lymphocyte subsets were tested with the Spearman's R. Analysis and graphs were made with Microsoft Excel 2010 and Stata 9.0 and with the SPSS Statistical package version 25. The Flow Cytometry results were analyzed using the Kaluza software version 2.1.

\section{RESULTS}

\section{Detection of Microchimerism}

Microchimerism was detected in both groups but was significantly more prominent in the patient group (52/64 $\approx 81.2 \%)$ compared to the control group $(6 / 21 \approx 28.5 \%, p$ $=0.0001$; Figure 2). The detection of chimeric alleles among the controls could be interpreted in the context of persistent maternal microchimerism, as has previously described $(10,21-$ 24). The quantification of the detected microchimerism, in terms of evaluating the number of chimeric alleles and the duration of the phenomenon, showed that the number of chimeric alleles in the control group did not exceed two, whereas in the patient group it reached up to seven chimeric alleles per patient tested (Figure 2). Twenty-two out of 64 patients (34.4\%) had evidence of long-term TA-MC, 8 (12.5\%) patients of only short-term, whereas the remaining $22(34.4 \%)$ exhibited both short- and long-term TA-MC. In 7 (33.3\%), among the 21 patients with NTDT, for whom microchimerism was confirmed at three time points, the gradual appearance of six new, but also the disappearance of four previously existing short-term chimeric polymorphisms, during a median period of 26.4 months was observed (Figure 3). No control subject was retested as the interpretation for them was a chronically existing maternal microchimerism $(10,21-24)$.
TABLE 4 | Patient demographics and main clinical and laboratory characteristics associated with TA-MC status.

\begin{tabular}{|c|c|c|c|}
\hline $\begin{array}{l}\text { Characteristics of } 64 \\
\text { subjects }\end{array}$ & $\begin{array}{l}\text { Number and } \\
\text { percentage } \\
(\%) \text { of } \\
\text { microchimeric }\end{array}$ & $\begin{array}{l}\text { Average of } \\
\text { chimeric } \\
\text { alleles } \pm \\
\text { standard } \\
\text { deviation }\end{array}$ & $\boldsymbol{P}$ \\
\hline \multicolumn{4}{|l|}{ Sex } \\
\hline Male (32) & 22 (68.7\%) & $1.15 \pm 0.97$ & 0.0004 \\
\hline Female (32) & 30 (93.7\%) & $2.46 \pm 1.69$ & \\
\hline \multicolumn{4}{|l|}{ Age } \\
\hline Median: 33.6 (31) & $24(77.4 \%)$ & $1.35 \pm 1.00$ & 0.021 \\
\hline Median: 52.5 (33) & $28(84.8 \%)$ & $2.24 \pm 1.79$ & \\
\hline \multicolumn{4}{|l|}{ Transfusion frequency } \\
\hline High (38) & 32 (84.2\%) & $1.89 \pm 1.47$ & 0.040 \\
\hline Intermediate (16) & $14(87.5 \%)$ & $2.19 \pm 1.78$ & \\
\hline Low (10) & $6(60 \%)$ & $0.90 \pm 0.83$ & \\
\hline \multicolumn{4}{|l|}{ Splenectomized } \\
\hline No (28) & 22 (78.5\%) & $1.39 \pm 1.01$ & 0.054 \\
\hline Yes (36) & 30 (83.3\%) & $2.13 \pm 1.76$ & \\
\hline \multicolumn{4}{|l|}{ Autoimmune disorder } \\
\hline No (60) & 48 (80\%) & $1.71 \pm 1.46$ & 0.052 \\
\hline Yes (4) & $4(100 \%)$ & $3.25 \pm 1.78$ & \\
\hline \multicolumn{4}{|l|}{ Pregnancy } \\
\hline No (24) & 22 (91.6\%) & $2.41 \pm 1.70$ & 0.712 \\
\hline Yes (8) & $8(100 \%)$ & $2.62 \pm 1.65$ & \\
\hline \multicolumn{4}{|l|}{ Endocrinal disorders } \\
\hline No (9) & 9 (100\%) & $1.77 \pm 1.22$ & 0.906 \\
\hline Yes (55) & $43(78.1 \%)$ & $1.81 \pm 1.57$ & \\
\hline \multicolumn{4}{|l|}{ Cardiac disorders } \\
\hline No (43) & 37 (86\%) & $1.81 \pm 1.35$ & 0.921 \\
\hline Yes (21) & $15(71.4 \%)$ & $1.80 \pm 1.84$ & \\
\hline \multicolumn{4}{|l|}{ HCV infection } \\
\hline No (41) & $36(87.8 \%)$ & $2.02 \pm 1.45$ & 0.098 \\
\hline Yes (23) & $16(69.5 \%)$ & $1.43 \pm 1.58$ & \\
\hline \multicolumn{4}{|l|}{ Past HBV infection } \\
\hline No (37) & 30 (81\%) & $1.86 \pm 1.59$ & 0.734 \\
\hline Yes (27) & $22(81.4 \%)$ & $1.74 \pm 1.42$ & \\
\hline \multicolumn{4}{|c|}{ Lymphocytes total number ${ }^{*}$} \\
\hline$(1,000-2,321)$ & 25 (83.3\%) & $1.80 \pm 1.4$ & 0.982 \\
\hline$(2,419-7,200)$ & $22(81.4 \%)$ & $1.79 \pm 1.7$ & \\
\hline \multicolumn{4}{|c|}{$\Gamma$-globulins total amount ${ }^{\star *}$} \\
\hline$(533-1,490)$ & 27 (77.1\%) & $1.94 \pm 1.68$ & 0.437 \\
\hline$(1,500-2,744)$ & $24(85.7 \%)$ & $1.64 \pm 1.31$ & \\
\hline \multicolumn{4}{|l|}{ Ferritin median value } \\
\hline$(85-4,667)$ & 49 (85.9\%) & $1.94 \pm 1.53$ & 0.041 \\
\hline$(5,049-7,641)$ & $3(42.8 \%)$ & $0.71 \pm 0.88$ & \\
\hline
\end{tabular}

Female patients of more advanced age, more heavily transfused with higher serum ferritin levels were associated with stronger and longer-standing microchimerism. TA-MC, transfusion-associated microchimerism. *Data was available for 59 patients. ${ }^{* *}$ Data was available for 63 patients. Statistically significant results are depicted in bold.

\section{Association of TA-MC With Potential Contributing Factors}

To identify potential contributing factors that might influence TA-MC development among thalassemic patients, we 


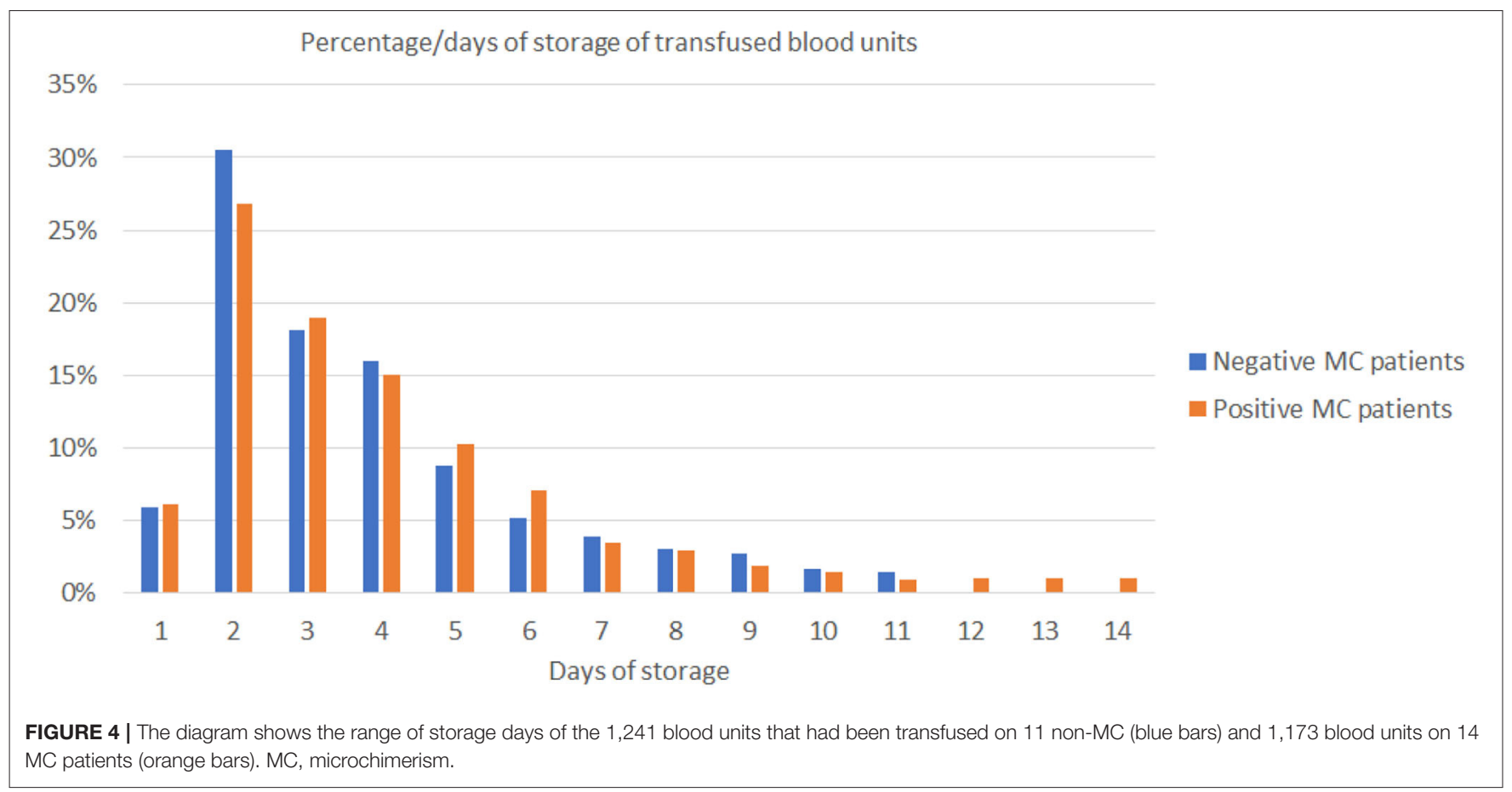

investigated the relationship of detected TA-MC with patients' clinical features. Gender $(p<0.004)$, age $(p=0.021)$, transfusion frequency (low: $\leq 6$, intermediate: 6-20, high: $>20$ transfused $\mathrm{RBC}$ units/year; $p=0.043)$, and serum ferritin levels $(p=0.041)$ were significantly correlated with the number of chimeric alleles detected (Table 4). Moreover, previous splenectomy $(p=0.054)$ and the presence of autoimmune disorders $(p=0.052)$ showed an association of borderline significance. We furthermore examined parameters related to the transfusion process, such as the storage time of RBC units and donor's gender. Totally, 2,414 RBC units transfused over a median period of 44 months were examined. For 11 patients without established TA-MC. the median storage time of transfused units was 4.54 days and $75 \%$ of the donors were men. Similarly, for 14 patients exhibiting the highest number of chimeric alleles, the median storage time was 4.24 days and $74.5 \%$ of the donors were men (p:n.s) (Figure 4). Thus, no association between these two parameters and microchimerism establishment was proved. Gestation was also investigated as a potential risk factor for microchimerism development, in combination with the transfusion therapy of the thalassemic women, but again, no significant association was found.

\section{Flow Cytometry Analysis}

The possibility that underlying immune dysregulation might influence TA-MC development or even the reverse (25), meaning that TA-MC might affect immune homeostasis, prompted us to investigate the peripheral blood immunological profile of these patients. The major T-cell subpopulations (CD3+, $\mathrm{CD} 4+$, and $\mathrm{CD} 8+$ ), their memory subsets (CD45RO+), $B$ cells $(\mathrm{CD} 20+)$, and their activation status (assessed by HLA-DR and CD25 expression on the CD3+ and CD4+ lymphocytes) did not exhibit any significant difference when compared between patients with ascending number of chimeric alleles (Table 5). However, a significant correlation between the number of detected chimeric alleles and the proportion of $\mathrm{CD} 3+\mathrm{CD} 25^{\text {bright }}+$ (a population in which regulatory $\mathrm{T}$-cells are included) was found (Table 5). Further investigation revealed significant alterations, proportional to the microchimerism grade, for selected lymphocyte subpopulations with known immunoregulatory properties, such as NK, NK/T, and regulatory T-cells. Table 5 displays all results of the lymphocyte subpopulations, examined across patients' groups, as defined by the number of chimeric alleles detected by PCR and their statistical significance. Displayed results are the following: the Spearman correlation; either positive or negative, suggesting a potential favorable/unfavorable/independent role that each population holds, regarding the establishment and the grade of microchimerism detected, and the independent samples Kruskal-Wallis and median tests statistical significance, depicting the differences in distributions and medians of the populations across patient groups with different chimeric alleles.

The same investigational approach was then applied for subcohorts of patients, characterized by their disease subtype and splenectomy status (transfusion dependent vs. non-transfusion dependent and splenectomized vs. non-splenectomized) in order to examine the effect of these major factors on the immunological profile of the patients. These findings are discussed below.

\section{NK-Cells}

The following NK-cell subsets were examined: $\mathrm{CD} 16^{\mathrm{dim}}+\mathrm{CD} 56^{\mathrm{dim}}+$ and $\mathrm{CD} 16^{\text {bright }}+\mathrm{CD} 56^{\text {bright }}+$ (classical $^{\text {da }}$ NK-cells), NK/T cells, and NK/T cells with $\mathrm{CD} 3^{\text {high }}$ expression 
TABLE 5 | Results for the major lymphocyte subpopulations, examined across patients' groups, defined by the number of chimeric alleles detected by PCR.

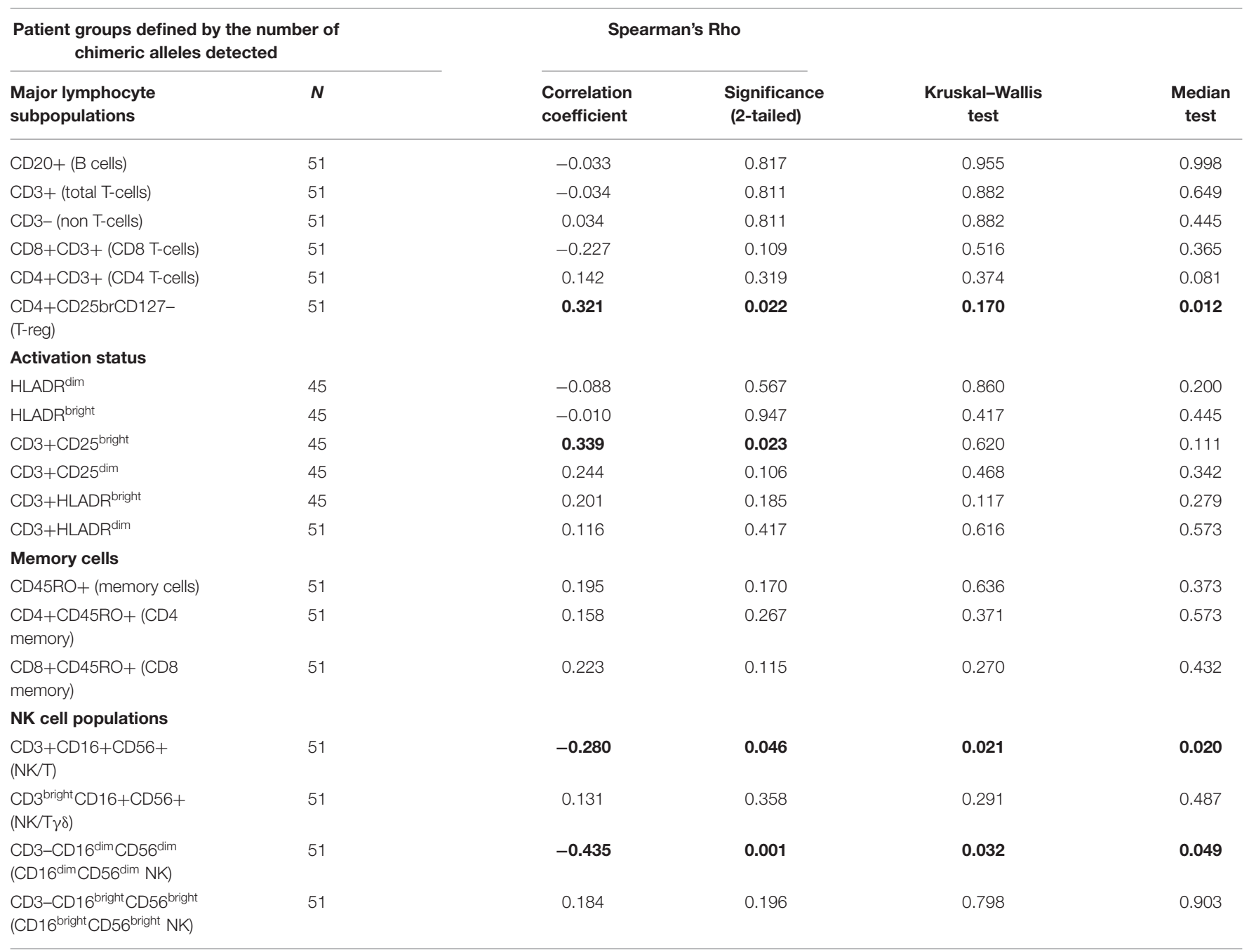

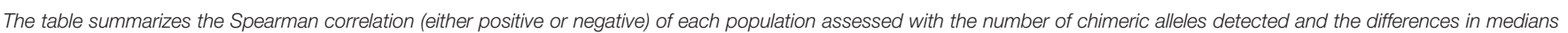

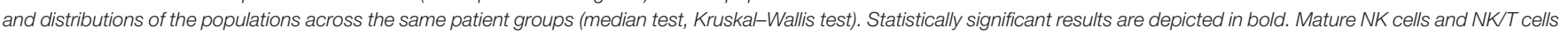

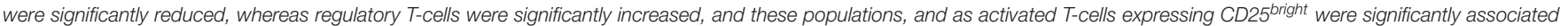
with higher number of detected chimeric alleles in patients' peripheral blood.

(probably $\mathrm{NK} / \mathrm{T}_{\gamma \delta}$ ). Median proportions of NK-cell subsets across patient groups exhibiting a different number of chimeric alleles were then compared. The percentage of $\mathrm{CD} 3-\mathrm{CD} 16^{\mathrm{dim}}+\mathrm{CD} 56^{\mathrm{dim}}+$ cells showed a statistically significant difference between the 6 patient groups, exhibiting a descending pattern, as the detected chimeric allelic burden was increasing (Kruskal-Wallis $p=0.032$; Figure 5). NK/T-cells $(\mathrm{CD} 3+\mathrm{CD} 16+\mathrm{CD} 56+)$ also exhibited a statistically significant difference, but with a less prominent proportional relationship with the number of chimeric alleles. The major NK-cell population $\left(\mathrm{CD} 3-\mathrm{CD} 16^{\text {bright }}+\mathrm{CD} 56^{\text {bright }}+\right)$ did not show any significant difference. Results of the investigated NK-cell subpopulations are presented in Table $\mathbf{5}$ and comparative flow cytometry analysis (plots) from two patients, one not exhibiting microchimerism vs. another with high allelic burden, is depicted in Figure 6.

\section{Regulatory T-Cells}

Regulatory T-cells were identified as the CD127 negative/dim subset of CD4+CD25 bright T-cells (CD3+) (as shown in Figure 7). Intracellular staining of transcriptional factor FoxP3 was omitted since CD127 is an adequate surrogate marker for T-reg identification (26) for a broad-analysis spectrum panel for lymphocytic subpopulations, as the one we developed for this study with the further advantage of making it more time- and cost-effective with the prospect of analyzing as many samples as possible. Independent sample median test showed statistically significant difference for the regulatory $\mathrm{T}$ cell proportions, among patients with a different allelic burden ( $p=0.012$, Figure 8). Patients without TA-MC or those with a low number of detected chimeric alleles had the lowest percentages, whereas the subset expanded as the number of alleles increased. Examples of T-reg identification and enumeration in 


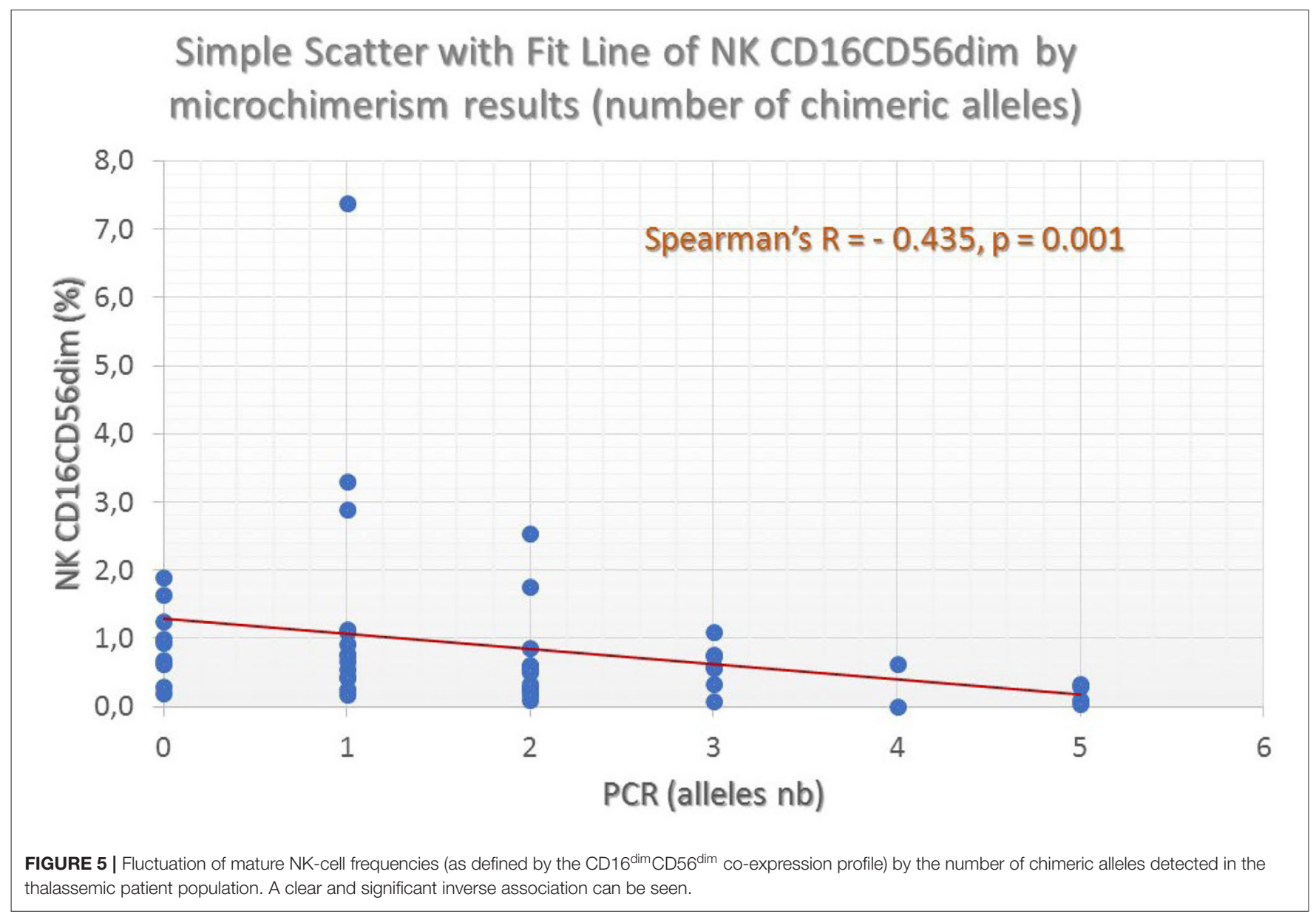

two patients with different chimeric allelic burden are displayed in Figure 7.

\section{Analysis of Patient Sub-Cohorts}

Non-transfusion-dependent thalassemia patients exhibited a distinct ascending CD4+ lymphocyte pattern, as the number of chimeric alleles was increased (independent samples median test $p=0.056$ ), however, the same was not true for all patients with TDT. Among previously splenectomized patients with $\operatorname{NTDT}(N=11)$, those exhibiting TA-MC with $\geq 2$ chimeric alleles $(N=4)$ had higher (although not significantly) percentage of $\mathrm{CD} 4+\mathrm{CD} 45 \mathrm{RO}+$ memory $\mathrm{T}$-cells, the reverse pattern of decreased CD $16^{\mathrm{dim}}+\mathrm{CD} 56^{\mathrm{dim}}$ NK-cells (0.29 vs. $0.76 \%$, independent samples median test $p=0.26$, MannWhitney test $p=0.007$ ), and increased CD16 $6^{\text {bright }}$ mature NKcells, when compared to the remaining seven, who exhibited $<2$ chimeric alleles (17.9 vs. $13.0 \%$, independent samples median test $p=0.26$, Mann-Whitney test $p=0.004)$.

Splenectomized patients with TDT $(N=14,5$ with $>2$ chimeric alleles, 9 with $\leq 2$ ) exhibited also similar results $\left(\mathrm{CD} 16^{\mathrm{dim}}+\mathrm{CD} 6^{\mathrm{dim}}+\right.$ cells: 0.54 vs. $1.25 \%$, independent samples median test $p=0.54$, Mann-Whitney test, $p=0.10)$. Nonsplenectomized TDT patients $(N=24: 20$ with $\leq 2$ alleles, 4 with
$>2$ chimeric alleles) exhibited slightly increased regulatory Tcells, $(0.76$ vs. $0.68 \%)$ and CD $56^{\text {dim }}+$ cells $(0.58$ vs. $0.34 \%)$ and decreased T/NK cells (4.12 vs. $5.80 \%)$ and memory T-cells (34.3 vs. $40.6 \%)$ as the number of the microchimeric alleles increased to $>2$. However, due to the small number of non-splenectomized patients with NTDT $(N=2)$, all differences were not statistically significant hence we did not perform further investigation (10, $18-20,21-24,26-28,29,30)$.

\section{DISCUSSION}

Microchimerism represents a complicated phenomenon, and several mechanisms are involved in its establishment. Moreover, many questions, related to the factors affecting its development and persistence for shorter or longer periods, among subjects exposed to similar predisposing conditions, still remain unanswered. Two important findings have emerged from this study. First, we have confirmed that patients with TDT, receiving lifelong RBC transfusions, commonly develop TA-MC even when transfused units are leuco-reduced, and second, we have demonstrated that TA-MC is associated with immune changes in the T-regs and some NK-cell subsets. Whether leuco-reduction is protective is contradictory, according to the published relevant information in other patient populations (18-20, 23-25). 


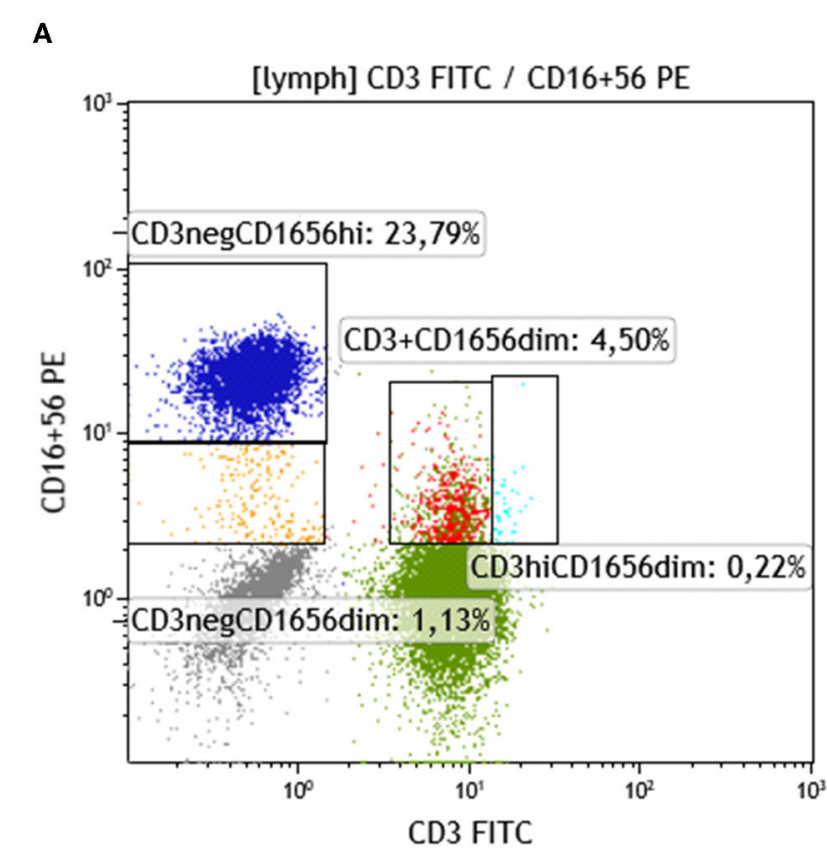

B
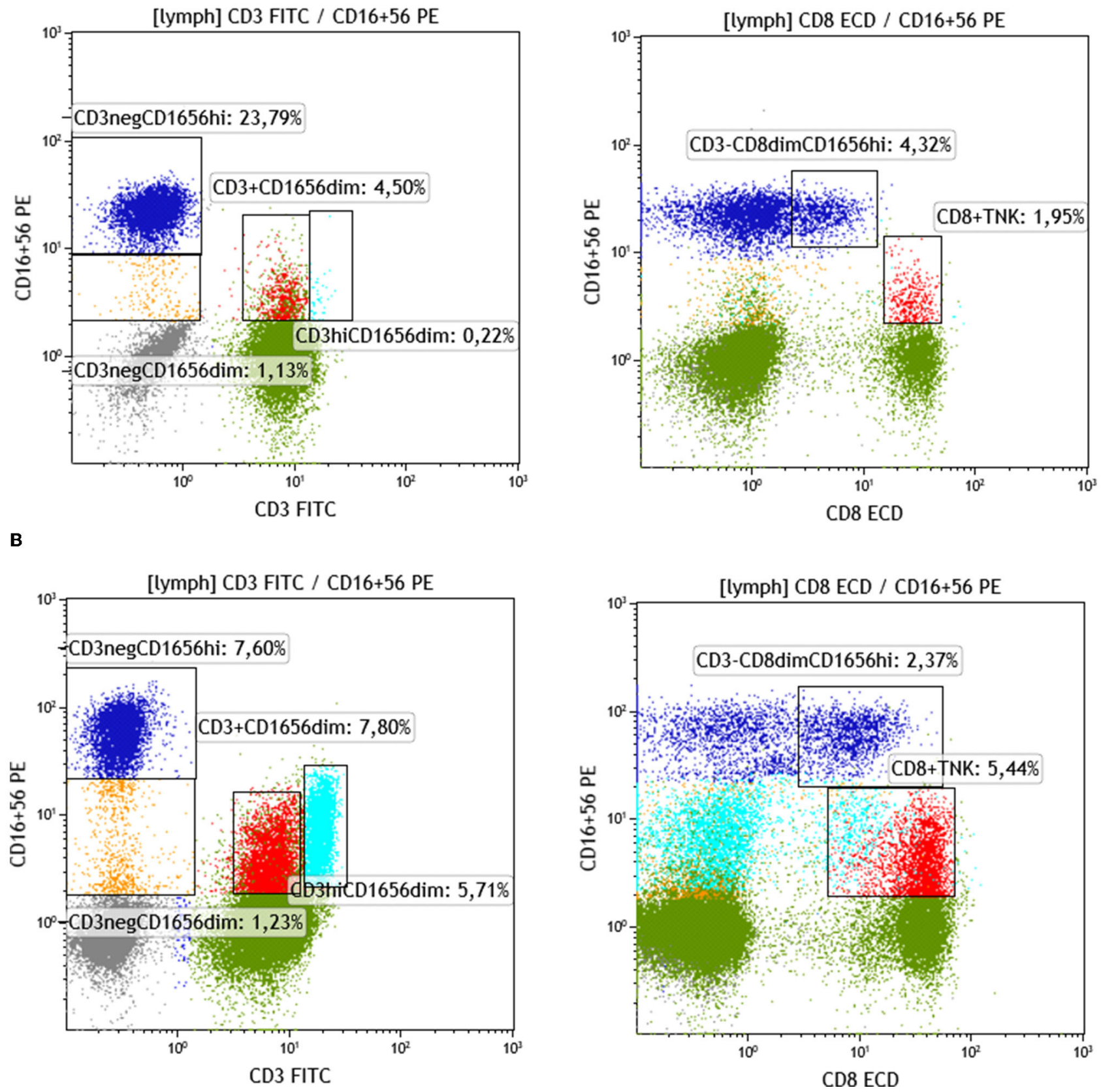

FIGURE 6 | Identification and quantification of NK and NKT in patients with a different allelic burden. (A) Patient with no chimeric alleles detected. (B) Patient with three chimeric alleles detected (splenectomized) (green: CD3+ non-NK, gray: CD3- non-NK, blue: NK CD56CD16 ${ }^{\text {br }}$, red: CD8+NKT, turquoise: CD3 ${ }^{\text {br }}$ T/NK yellow: NK CD56CD16 dim).

We have not approached this issue, since in our Hospital all immunocompromised, TDT, and other multi-transfused patients only receive leuco-reduced blood products, according to the European Council guidelines (the leukocyte content in the blood components we used is $1 \times 10^{6}$ per unit, i.e., 95\% CI). In our study, the high rate of microchimerism detected among healthy controls was somewhat surprising, however, similar results have also been obtained from previous studies and are interpreted in the context of persistent maternal microchimerism (10, 21-24). A small proportion might also be considered false positive, due to a high sensitivity of the PCR reagents we used. All control subjects tested, continue to donate blood and during the subsequent two to four years they did not report any problem of their health. However, the observed high frequency of TA-MC 


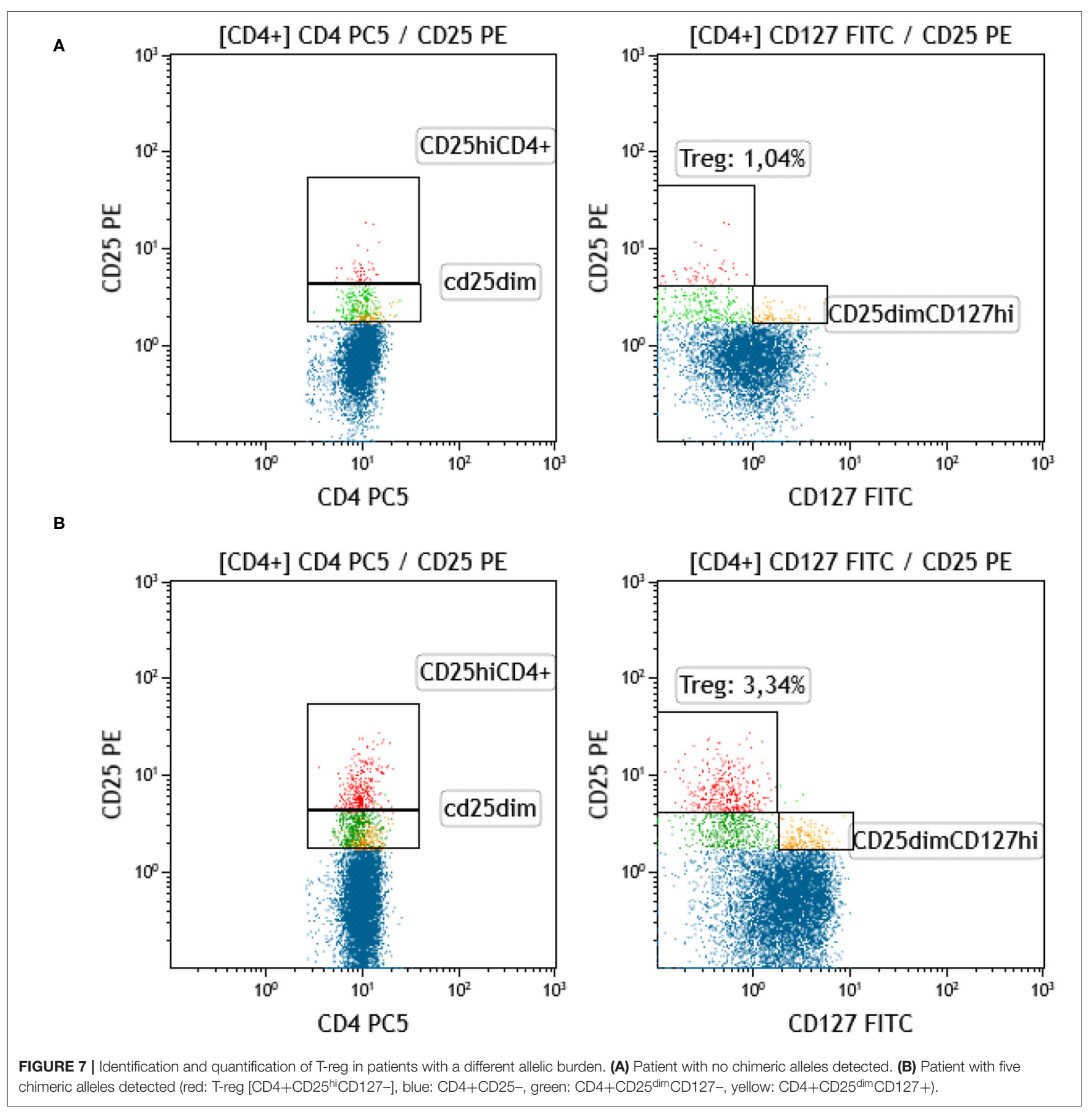

among thalassemic patients, and particularly, the high number of detected alleles can only be attributed to RBC transfusions. The obtained significant association between the number of detected chimeric alleles and serum ferritin levels, reflecting transfusion burden, supports this notion. Irradiation appears to significantly reduce the risk of TA-MC (27). Previous studies, mainly performed on trauma patients, have demonstrated that storage time was a predictor for TA-MC development. We were unable to confirm this finding. A potential explanation might be that different pathogenetic mechanisms that drive TA-MC generation in patients with TDT, compared to those occurring in trauma patients, and specific immunomodulatory conditions, attributed to the disease itself and/or to the chronic transfusion program, are developed in patients with TDT, favoring the generation of microchimerism.

Microchimerism reflects the presence of donor-derived antigenic and/or genetic material that evades immunologic surveillance of the recipient, most probably through the 


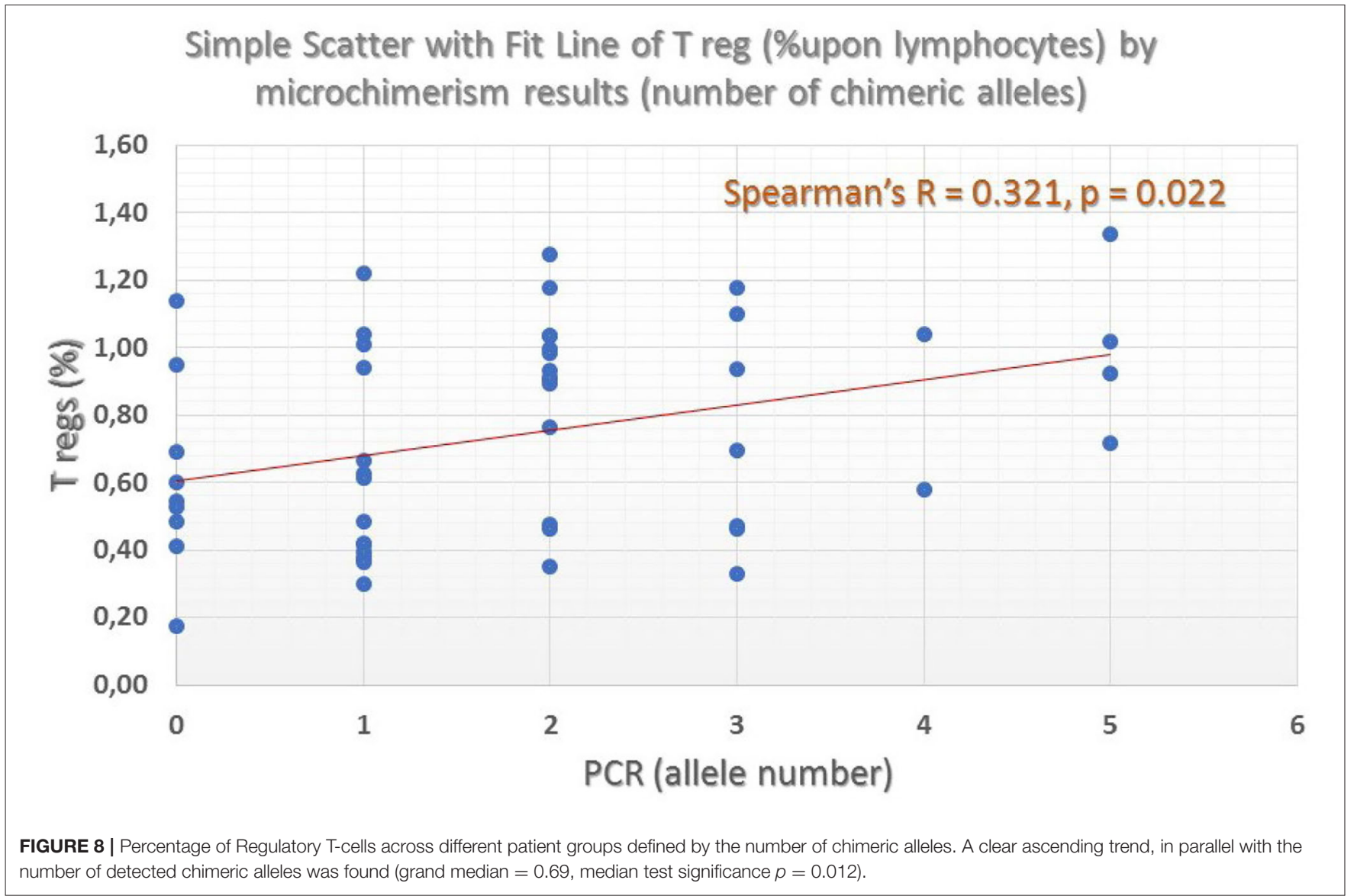

induction of tolerance. Immune tolerance might both, pre-exist and also, be induced or exacerbated by the repeated $\mathrm{RBC}$ transfusions. The persistence of donor's derived allogeneic lymphocytes or even diluted allogeneic HLA-antigens in the recipient's blood is both, favored by pre-existing immune tolerance, and induces further tolerogenic changes. In the majority of cases, this immunomodulation is incapable to induce transfusion-associated Graft versus Host Disease (GvHD), because the latter requires a larger quantity of donor lymphocytes, which must survive the recipient's cytotoxic reaction, recognize alloantigens, and orchestrate an immune response against the donor. When transfused lymphocytes are few and repeatedly administered, a type-II immune response might be induced, induced by the multiple antigenic stimuli, leading to immune tolerance. Immune tolerance increases the residence time of allogeneic cells in the recipient's blood and generates TA-MC. Type-II immune response might be stronger in cases of long-term microchimerism, as it has been shown in a well-designed prospective randomized French study on 37 cancer patients, on whom TA-MC was associated with a clear immunomodulation toward Th2 direction (28).

In our study, TDT patients with higher chimeric allelic burden exhibited a distinct immunologic profile, characterized by CD4+ T-lymphocyte (such as T-regs) expansion and by decreased NK-cell subsets. These findings reflect the existence of immune tolerance, which allows or even favors TA-MC development, through the immunomodulatory/immunosuppressive functions of T-regs and the lack of certain cytolytic effects of NK cells. The differences observed in various NKcell subsets, especially among splenectomized patients, would be difficult to assess, considering the well-known persistent post-splenectomy NK lymphocytosis. Splenectomy might play an additional role in the expansion of the phenomenon since splenectomized patients usually exhibit higher percentages of T-regs and higher microchimeric allelic burden.

Immune tolerance, resulting from potential donor/recipient genotype relationship, should also be taken into consideration, especially in "closed" populations, living in small geographic areas, where blood donors and recipients may retain probabilities to be distantly related. To this point, the increased number of repeated detection of 7 alleles out of the 24 tested [S02, S04B, DR3, DR4, DR13, DR15, and DR16] (Figure 3), may partially be attributed to this explanation. Investigation of larger cohorts of multi-transfused patients and untransfused controls may clarify potentially existing predisposing factors for TA-MC development and for its prognostic significance. Clinically speaking, the previous $\gamma$-irradiation of all blood products and compliance with updated blood transfusion management protocols could be 
recommended, to avoid potentially as yet unknown consequences of microchimerism.

\section{CONCLUSION}

The majority of multi-transfused thalassemic patients exhibit TAMC in their peripheral blood. Risk factors for the establishment of microchimerism in this patient population are gender, age, and transfusion frequency. NK-T cell increase, usually postsplenectomy, but also T-reg imbalance, appears to influence TAMC development and perpetuation, favoring the establishment of immune tolerance against allogeneic cells. Leucodepletion and blood storage time do not influence the appearance and duration of TA-MC.

\section{LIMITATIONS OF THIS STUDY}

This study aimed to demonstrate the presence of both, short and long-term TA-MC among multitransfused patients with $\beta$-thalassemia, since there was no information about this late consequence in the thalassemic patient population. It has not focused on the investigation of the presence of maternal microchimerism among the normal control subjects. Thus, controls have been tested only once and not longitudinally, to establish the frequency of existing long-term MC, relying on the results of previous studies. Moreover, this study has not investigated potential correlation of TA-MC with any clinical feature in the course and evolution of $\beta$-thalassemic patients, such as frequency of transfusion-induced alloimmunization, or the manifestation of autoimmune and neoplastic diseases at longterm follow up. Although we did not find an obvious correlation with any clinical parameter or feature of the patients during the study period, this issue requires further and in depth clinical investigation, which will be the aim of another study.

\section{DATA AVAILABILITY STATEMENT}

The original contributions presented in the study are publicly available. This data can be found here: https://doi.org/10.6084/ m9.figshare.14646657.

\section{REFERENCES}

1. Taher AT, Weatherall DJ, Cappellini MD. Thalassaemia. Lancet. (2018) 391:155-67. doi: 10.1016/S0140-6736(17)31822-6

2. Weatherall DJ. The inherited diseases of hemoglobin are an emerging global health burden. Blood. (2010) 115:4331-6. doi: 10.1182/blood-2010-01-2 51348

3. Voskaridou E, Ladis V, Kattamis A, Hassapopoulou E, Economou M, Kourakli A, et al. A national registry of haemoglobinopathies in Greece: deducted demographics, trends in mortality and affected births. Ann Hematol. (2012) 91:1451-8. doi: 10.1007/s00277-0121465-7

4. Vichinsky E, Neumayr L, Trimble S, Giardina PJ, Cohen AR, Coates T, et al. Transfusion complications in thalassemia patients: a report from the Centers for Disease Control and Prevention (CME). Transfusion. (2014) 54:972-81; quiz 971. doi: 10.1111/trf.12348

\section{ETHICS STATEMENT}

The studies involving human participants were reviewed and approved by Tzaneion Hospital Ethics and Scientific Committee, 5th issue of the 17th Meeting of the Committee in 13.6.2012. The patients/participants provided their written informed consent to participate in this study.

\section{AUTHOR CONTRIBUTIONS}

SM, MK, and AS designed the project. SM also performed PCR experiments, analyzed data, and co-wrote the paper. EV designed and performed Flow Cytometry experiments, analyzed data, and co-wrote the paper. AK supervised and designed samples collection and patient's data collection. SA performed Flow Cytometry experiments. SV performed the statistical analysis. CAr performed samples collection and preservation. PS supervised and co-designed the PCR experiments. VLaz and VLab offered the clinical patient care and retrieved clinical data. NG collected blood products' storage time and gender data. ML performed the samples and the primers data preparation. CAl supervised the research. AS supervised the research and co-wrote the paper. All authors contributed to the article and approved the submitted version.

\section{FUNDING}

This research was supported by the research grants from the University of Patras.

\section{ACKNOWLEDGMENTS}

The author specially thank to Kleopatra Spanou, Chemist at the Immunology-Histocompatibility Department of the Haghia Sophia Children's Hospital in Athens, for her help, by offering the NanoDrop 2000 instrument for the experiments needs. Great thanks to Nikolaos Davanos, Biologist on Antisel Company for his contribution on this research, by offering StepOnePlus System for the experiments needs and his valuable advices.
5. Cappellini MD, Porter JB, Viprakasit V, Taher AT. A paradigm shift on beta-thalassaemia treatment: how will we manage this old disease with new therapies? Blood Rev. (2018) 32:300-11. doi: 10.1016/j.blre.2018.02.001

6. Reed W, Lee TH, Vichinsky EP, Lubin BH, Busch MP. Sample suitability for the detection of minor white cell populations (microchimerism) by polymerase chain reaction. Transfusion. (1998) 38:1041. doi: 10.1046/j.1537-2995.1998.38111299056314.x

7. Nelson JL. Microchimerism in human health and disease. Autoimmunity. (2003) 36:5-9. doi: 10.1080/0891693031000067304

8. Reed AM, Harwood A, Picornell YJ, Kredich DW. Chimerism in children with juvenile dermatomyositis. Lancet. (2000) 356:2156-7. doi: 10.1016/S0140-6736(00)03500-5

9. Artlett CM, Ramos R, Jiminez SA, Patterson K, Miller FW, Rider LG. Chimeric cells of maternal origin in juvenile idiopathic inflammatory myopathies. Childhood Myositis Heterogeneity Collaborative Group. Lancet. (2000) 356:2155-6. doi: 10.1016/S0140-6736(00)03499-1 
10. Gammill HS, Nelson JL. Naturally acquired microchimerism. Int J Dev Biol. (2010) 54:531-43. doi: 10.1387/ijdb.082767hg

11. Kinder JM, Stelzer IA, Arck PC, Way SS. Immunological implications of pregnancy-induced microchimerism. Nat Rev Immunol. (2017) 17:48394. doi: 10.1038/nri.2017.38

12. Schechter GP, Whang Peng J, McFarland W. Circulation of donor lymphocytes after blood transfusion in man. Blood. (1977) 49:6516. doi: 10.1182/blood.V49.4.651.bloodjournal494651

13. Utter GH, Owings JT, Lee TH, Paglieroni TG, Reed WF, Gosselin RC, et al. Blood transfusion is associated with donor leukocyte microchimerism in trauma patients. J Trauma Injury Infect Crit Care. (2004) 57:702-7; discussion 707-8. doi: 10.1097/01.TA.0000140666.15972.37

14. Lee TH, Paglieroni T, Utter GH, Chafets D, Gosselin RC, Reed $\mathrm{W}$, et al. High-level long-term white blood cell microchimerism after transfusion of leukoreduced blood components to patients resuscitated after severe traumatic injury. Transfusion. (2005) 45:1280-90. doi: 10.1111/j.1537-2995.2005.00201.x

15. Bloch EM, Jackman RP, Lee TH, Busch MP. Transfusion-associated microchimerism: the hybrid within. Transfus Med Rev. (2013) 27:1020. doi: 10.1016/j.tmrv.2012.08.002

16. Jackman RP, Utter GH, Lee TH, Montalvo L, Wen L, Chafets D, et al. Lack of persistent microchimerism in contemporary transfused trauma patients. Transfusion. (2019) 59:3329-36. doi: 10.1111/trf.15518

17. Utter GH, Lee TH, Rivers RM, Montalvo L, Wen L, Chafets DM, et al. Microchimerism decades after transfusion among combat-injured US veterans from the Vietnam, Korean, and World War II conflicts. Transfusion. (2008) 48:1609-15. doi: 10.1111/j.1537-2995.2008.01758.x

18. Hirani R, Balogh ZJ, Lott NJ, Hsu JM, Irving DO. Leukodepleted blood components do not remove the potential for long-term transfusion-associated microchimerism in Australian major trauma patients. Chimerism. (2014) 5:86-93. doi: 10.1080/19381956.2015.1052210

19. Alizadeh M, Bernard M, Danic B, Dauriac C, Birebent B, Lapart C, et al. Quantitative assessment of hematopoietic chimerism after bone marrow transplantation by real-time quantitative polymerase chain reaction. Blood. (2002) 99:4618-25. doi: 10.1182/blood.V99.12.4618

20. Lee TH, Chafets DM, Reed W, Wen L, Yang Y, Chen J, et al. Enhanced ascertainment of microchimerism with real-time quantitative polymerase chain reaction amplification of insertion-deletion polymorphisms. Transfusion. (2006) 46:1870-8. doi: 10.1111/j.1537-2995.2006.00992.x

21. Thompson EE, Myers RA, Du G, Aydelotte TM, Tisler CJ, Stern DA, et al. Maternal microchimerism protects against the development of asthma. $J$ Allergy Clin Immunol. (2013) 132:39-44. doi: 10.1016/j.jaci.2012.12.1575

22. Maloney S, Smith A, Furst DE, Myerson D, Rupert K, Evans PC, et al. Microchimerism of maternal origin persists into adult life. J Clin Invest. (1999) 104:41-7. doi: 10.1172/JCI6611
23. Loubière LS, Lambert NC, Flinn LJ, Erickson TD, Yan Z, Guthrie KA, et al. Maternal microchimerism in healthy adults in lymphocytes, monocyte/macrophages and NK cells. Lab Invest. (2006) 86:1185-92. doi: 10.1038/labinvest.3700471

24. Lambert NC, Erickson TD, Yan Z, Pang JM, Guthrie KA, Furst DE, et al. Quantification of maternal microchimerism by HLA-specific realtime polymerase chain reaction: studies of healthy women and women with scleroderma. Arthritis Rheum. (2004) 50:906-14. doi: 10.1002/art. 20200

25. Eikmans M, van Halteren AGS, van Besien K, van Rood JJ, Drabbels JJM, Claas FHJ. Naturally acquired microchimerism implications for transplantation outcome and novel methodologies for detection. Chimerism. (2014) 5:2439. doi: 10.4161/chim. 28908

26. Liu W, Putnam AL, Xu-yu Z, Szot GL, Lee MR, Zhu S, et al. CD127 expression inversely correlates with FoxP3 and suppressive function of human CD4+ T reg cells. J Exp Med. (2006) 203:1701-11. doi: 10.1084/jem.20060772

27. Reed W, Lee TH, Norris PJ, Utter GH, Busch MP. Transfusionassociated microchimerism: a new complication of blood transfusions in severely injured patients. Semin Hematol. (2007) 44:24-31. doi: 10.1053/j.seminhematol.2006.09.012

28. Flesland O, Ip LSK, Storlien AS, Spurkland A, Larsen J, Solheim BG. Microchimerism in immune competent patients related to the leukocyte content of transfused red blood cell concentrates. Transfus Apher Sci. (2004) 31:173-80. doi: 10.1016/j.transci.2004. 07.012

Conflict of Interest: The authors declare that the research was conducted in the absence of any commercial or financial relationships that could be construed as a potential conflict of interest.

Publisher's Note: All claims expressed in this article are solely those of the authors and do not necessarily represent those of their affiliated organizations, or those of the publisher, the editors and the reviewers. Any product that may be evaluated in this article, or claim that may be made by its manufacturer, is not guaranteed or endorsed by the publisher.

Copyright (c) 2022 Matsagos, Verigou, Kourakli, Alexis, Vrakas, Argyropoulou, Lazaris, Spyropoulou, Labropoulou, Georgara, Lykouresi, Karakantza, Alepi and Symeonidis. This is an open-access article distributed under the terms of the Creative Commons Attribution License (CC BY). The use, distribution or reproduction in other forums is permitted, provided the original author(s) and the copyright owner(s) are credited and that the original publication in this journal is cited, in accordance with accepted academic practice. No use, distribution or reproduction is permitted which does not comply with these terms. 